\title{
The effect of gallium nitride on long-term culture induced aging of neuritic function in cerebellar granule cells
}

\author{
Chi-Ruei Chen, Tai-Horng Young* \\ Institute of Biomedical Engineering, College of Medicine and College of Engineering, \\ National Taiwan University, Taipei 100, Taiwan, ROC \\ Received 1 August 2007; accepted 26 November 2007 \\ Available online 14 January 2008
}

\begin{abstract}
Gallium nitride $(\mathrm{GaN})$ has been developed for a variety of microelectronic and optical applications due to its unique electric property and chemical stability. In the present study, n-type and p-type GaN were used as substrates to culture cerebellar granule neurons to examine the effect of $\mathrm{GaN}$ on cell response for a long-term culture period. It was found that GaN could rapidly induce cultured neurons to exhibit a high phosphorylated Akt level after $20 \mathrm{~h}$ of incubation. It was assumed that the anti-apoptotic effect of Akt phosphorylation could be correlated with cell survival, neurite growth and neuronal function for up to 35 days of incubation. Morphological studies showed GaN induced larger neuronal aggregates and neurite fasciculation to exhibit a dense fiber network after 8 days of incubation. Western blot analysis and immunocytochemical characterization showed that GaN still exhibited the expression of neurite growth and function, such as high levels of GAP-43, synapsin I and synaptophysin even after 35 days of incubation. In addition, survival of cerebellar granule neurons on GaN was improved by the analysis of lactate dehydrogenase (LDH) release from damaged cells. These results indicated that neuronal connections were formed on GaN by a gradual process from Akt activation and cell aggregation to develop neurite growth, fasciculation and function. Therefore, GaN offers a good model system to identify a well-characterized pattern of neuronal behavior for a long-term culture period, consistent with the development of a neurochip requiring the integration of biological system and semiconductor material.
\end{abstract}

(C) 2007 Elsevier Ltd. All rights reserved.

Keywords: Gallium nitride (GaN); Cerebellar granule neurons; Long-term culture

\section{Introduction}

Gallium nitride $(\mathrm{GaN})$ is a so-called III-V compound semiconductor material with unique physical and chemical properties such as chemical stability, hardness and electric properties [1-4]. Thus, GaN has been a subject of intense recent investigation and has emerged as attractive candidate for a variety of microelectronic [1] and optical [5,6] applications. Such advantages make GaN a good candidate in integrating electronics and biological system to develop biochips for different biomedical applications. Recently, the development of

\footnotetext{
* Corresponding author. Institute of Biomedical Engineering, College of Medicine, National Taiwan University, no. 1, Section 1, Jen-Ai Road, Taipei 100, Taiwan, ROC. Tel.: +886 2 23123456x1455; fax: +886223940049.

E-mail address: thyoung @ntu.edu.tw (T.-H. Young).
}

neurochips for stimulation and signal collection from cultured neurons attracts a lot of attention $[7,8]$. From the technological point of view, tight adhesion of mammalian neurons to an appropriate chip surface is a prerequisite. At present, almost all developed chips for neural system are silicon-based devices [9]. Since the biocompatibility of silicon is poor, coating the surface with bioactive molecules such as poly-D-lysine (PDL) or laminin have been used to promote cell adhesion and survival [10]. However, coating bioactive molecules on the substrate is non-covalent attachment, which may be lost by washing steps, thus, it is a non-permanent modification. More efficient methods of promoting direct cell adhesion to the chip surface would be very valuable. Thus, in our laboratory, we tried to develop more neuron-favorable chip materials to promote cell adhesion to the chip surface. In the previous study [11], GaN has been shown to mediate the response of 
cerebellar granule neurons to promote cell differentiation and neuritic growth during 6 days of culture period. However, the novel function of GaN applied to culture cerebellar granule neurons for a longer period has not been established.

In the present study, $\mathrm{GaN}$ was used as a substrate for culture of cerebellar granule neurons for up to 35 days to examine its effect on cell response after a long-term culture period. Similar to the previous study [11], n-type and p-type GaN were used to culture cerebellar granule neurons prepared from 7-day-old Wistar rats. These two types of GaN have different surface compositions. The surface of the p-type GaN surface was enriched with gallium and that of the n-type $\mathrm{GaN}$ surface with nitride [12]. For comparison, commercial tissue culture polystyrene (TCPS) and PDL-coated TCPS were also used to culture cells. TCPS is the standard substrate for culturing various cells. PDL is a commonly used coating material in the preparation of neuronal cultures. At first, we investigated whether the specific protein-dependent signaling pathway was responsible for the neuronal survival and differentiation on GaN. Recent evidence indicates that the serine/threonine protein kinase PKB (PKB; also known as Akt) plays an important role in signal transduction $[13,14]$, which regulates cell survival, growth, glucose transport and energy metabolism [15]. In this study, it was found that Akt was rapidly activated by GaN during the first $20 \mathrm{~h}$ of cell culture, which is thought to be related to the neuronal behavior after a long-term culture period. After 8 days of incubation, morphological studies of cultured neurons showed that GaN induced the neurite fasciculation and exhibited a dense fiber network from neuronal aggregates. After incubation for 35 days, it was found by Western blot analysis and immunocytochemical characterization that GaN still exhibited the expression of neurite growth and function, such as high levels of GAP-43 [16,17], synapsin I $[18,19]$ and synaptophysin [20]. In addition, survival of cerebellar granule neurons on $\mathrm{GaN}$ was improved by the analysis of lactate dehydrogenase (LDH) release from damaged cells. These results indicated that neuronal connections were formed on $\mathrm{GaN}$ by a gradual process from Akt activation and cell aggregation to develop neurite growth, fasciculation and function. Therefore, GaN offers a good model system to identify a well-characterized pattern of neuronal behavior for a longterm culture period, consistent with the development of a neurochip requiring the integration of biological system and semiconductor material.

\section{Materials and methods}

\subsection{Sample preparation}

The substrates used in this study included n-type and p-type GaN (Huga Optotech Inc., Taiwan). All samples with a size of approximately $1 \mathrm{~cm}^{2}$ and a thickness of $1 \pm 0.1 \mathrm{~mm}$ were cleaned by sonification in water and $70 \%$ alcohol, sterilized with autoclave and then rinsed extensively with phosphate buffer solution (PBS). Subsequently, samples were placed in 24-well TCPS plates (Corning, New York, USA). The empty and PDL-coated wells where no sample was placed were used as controls. PDL was purchased from Sigma and diluted to $10 \mu \mathrm{g} / \mathrm{ml}$ in PBS. Before cell culture, wells were covered with $1 \mathrm{ml}$ of PDL diluted solution and incubated for $4 \mathrm{~h}$, after which time excess solution was removed by suction and dried for another hour.

\subsection{Cell culture}

Cerebellar granule neurons were prepared from 7-day-old Wistar rats according to Levi et al. [21] with slight modification. Briefly, neurons were dissociated from freshly dissected cerebella by mechanical disruption in the presence of trypsin and DNase. Subsequently, neurons were added to the culture wells at a density of $1 \times 10^{6}$ cells/well [22] in basal Eagle medium (BME; Gibco) supplemented with $10 \%$ fetal calf serum (unless specified), $25 \mathrm{~mm} \mathrm{KCl}$, penicillin $\mathrm{G}(100 \mathrm{IU} / \mathrm{ml})$ and streptomycin $(100 \mathrm{mg} / \mathrm{ml})$. Cultures were maintained at $37{ }^{\circ} \mathrm{C}$ in a humidified atmosphere of $95 \%$ air $-5 \% \mathrm{CO}_{2}$. Cytosine arabinoside $(10 \mathrm{~mm})$ was added to the culture medium 1 day after plating to prevent replication of non-neuronal cells.

\subsection{Cell morphology}

For morphological observation, the cells adhering to the sample were washed with PBS and then fixed with $2.5 \%$ glutaraldehyde in PBS for $1 \mathrm{~h}$ at $4{ }^{\circ} \mathrm{C}$. After thorough washing with PBS, the specimens were dehydrated by graded ethanol changes and then examined by a metallography microscope (Olympus BX51M, Japan) for GaN substrates or an inverse phase contrast microscope (Olympus IX71, Japan) for TCPS and PDL substrates. Detailed morphological analysis was performed on aggregated neurons by using a Hitachi S-800 scanning electron microscope (SEM), after specimens being critical point dried and gold sputtered in vacuum.

\subsection{Immunofluorescence microscopy}

For immunocytochemical characterization, cultured neurons were fixed in ice-cold 4\% paraformaldehyde in PBS for $25 \mathrm{~min}$ and washed three times in PBS after 35 days of incubation. Following fixing, neurons exposed to
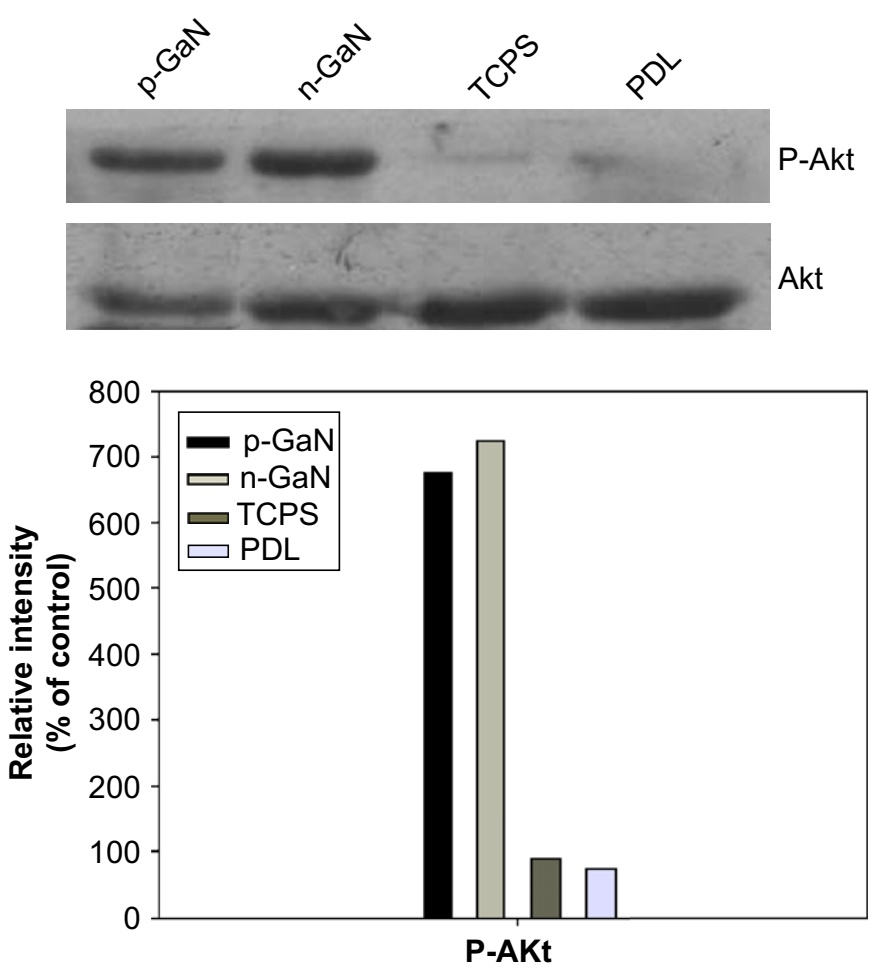

Fig. 1. Substrate-induced Akt phosphorylation in cerebellar granule neurons. Western blots were performed with anti-phosphorylated Akt and anti-Akt antibodies for cells cultured on n-type GaN, p-type GaN, TCPS, and PDL after $20 \mathrm{~h}$ of incubation. The bottom panel indicates the relative intensities of phosphorylated Akt levels, determined by band densitometry analysis. The ratio of the band intensities was expressed as a percentage of TCPS control. 
primary antibody (diluted in $10 \%$ BSA/PBS) overnight at $4{ }^{\circ} \mathrm{C}$. The primary antibodies and their dilution used in this study were rabbit anti-microtubuleassociated protein 2 polyclonal antibody (anti-MAP-2; 1:500; Chemicon), mouse anti-synapsin I protein monoclonal antibody (1:500; BD), and mouse anti-synaptophysin protein monoclonal antibody $(1: 500$; BD) $[23,24]$. FITCand rhodamine-conjugated secondary antibodies were used to visualize the signal by reacting with cells for $30 \mathrm{~min}$ at room temperature. The secondary antibodies and their dilutions were FITC-conjugated donkey anti-rabbit IgG (preabsorbed with rabbit and rat serum protein; 1:100; Chemicon, Temecula, $\mathrm{CA}$ ) and rhodamine-conjugated goat anti-mouse $\mathrm{IgG}$ (preabsorbed with rabbit and rat serum protein; 1:100; Chemicon, Temecula, CA). These immunostained cells were visualized by indirect fluorescence under the fluorescent microscope (Axiovert 100TV, Germany).

\subsection{Western blot analysis}

Cells were collected by gentle shaking of the wells and washed twice with PBS. Cell lysates were prepared with ice-cold lysis buffer $(20 \mathrm{~mm}$ Tris, pH 7.5, $150 \mathrm{~mm} \mathrm{NaCl}, 1$ mм EDTA, $10 \%$ glycerol, $1 \%$ Triton X-100, $1 \mathrm{~mm} \mathrm{NaF}, 1 \mathrm{~mm} \mathrm{Na} \mathrm{VO}_{4}, 1: 200$ dilution of Protease Inhibitor Cocktail II;
Calbiochem) for $30 \mathrm{~min}$ and then were sonicated at $4{ }^{\circ} \mathrm{C}$ for $15 \mathrm{~s}$. Lysates were clarified by centrifugation at $10,000 \mathrm{rpm}$ for $30 \mathrm{~min}$ at $4{ }^{\circ} \mathrm{C}$ and the resulting supernatant was saved for protein analysis and Western blot analysis. Protein concentration was measured by using the commercial protein assay reagent (Bio-Rad, Hercules, CA). For Western blotting, the supernatant was added to an equal volume of Laemmli sample buffer $(62.5 \mathrm{~mm}$ Tris, $\mathrm{pH} 6.8,25 \%$ glycerol, $2 \%$ SDS, $0.01 \%$ bromophenol blue, $5 \%$-mercaptoethanol) and heated to $95^{\circ} \mathrm{C}$ for $5 \mathrm{~min}$. Proteins $(50 \mu \mathrm{g}$ total protein per lane) were separated by SDS-PAGE on $10 \%$ polyacrylamide gels and transferred onto PVDF membranes. The membranes were blocked with 5\% non-fat milk in TBST buffer (Bio-Rad, Hercules, CA) and probed with a monoclonal mouse Akt and phospho(Ser ${ }^{473}$ )-Akt antibody (BD; 1:1000), a monoclonal mouse $\beta$-actin antibody (Chemicon; 1:2000), a monoclonal mouse GAP-43 antibody (BD; 1:10,000), a monoclonal mouse synapsin I antibody (BD; $1: 25,000)$ and a monoclonal mouse synaptophysin antibody (BD; $1: 25,000)$, and the membranes were incubated in primary antibody at $4{ }^{\circ} \mathrm{C}$ overnight. After washing, the blots were incubated with HRP secondary antibodies (1:5000) at room temperature for $2-3 \mathrm{~h}$. Finally, the proteins on the membranes were detected using the ECL Plus chemiluminescence system. Densitometric quantification of Western blots was done using software of AlphaEase FC (version 4.0).
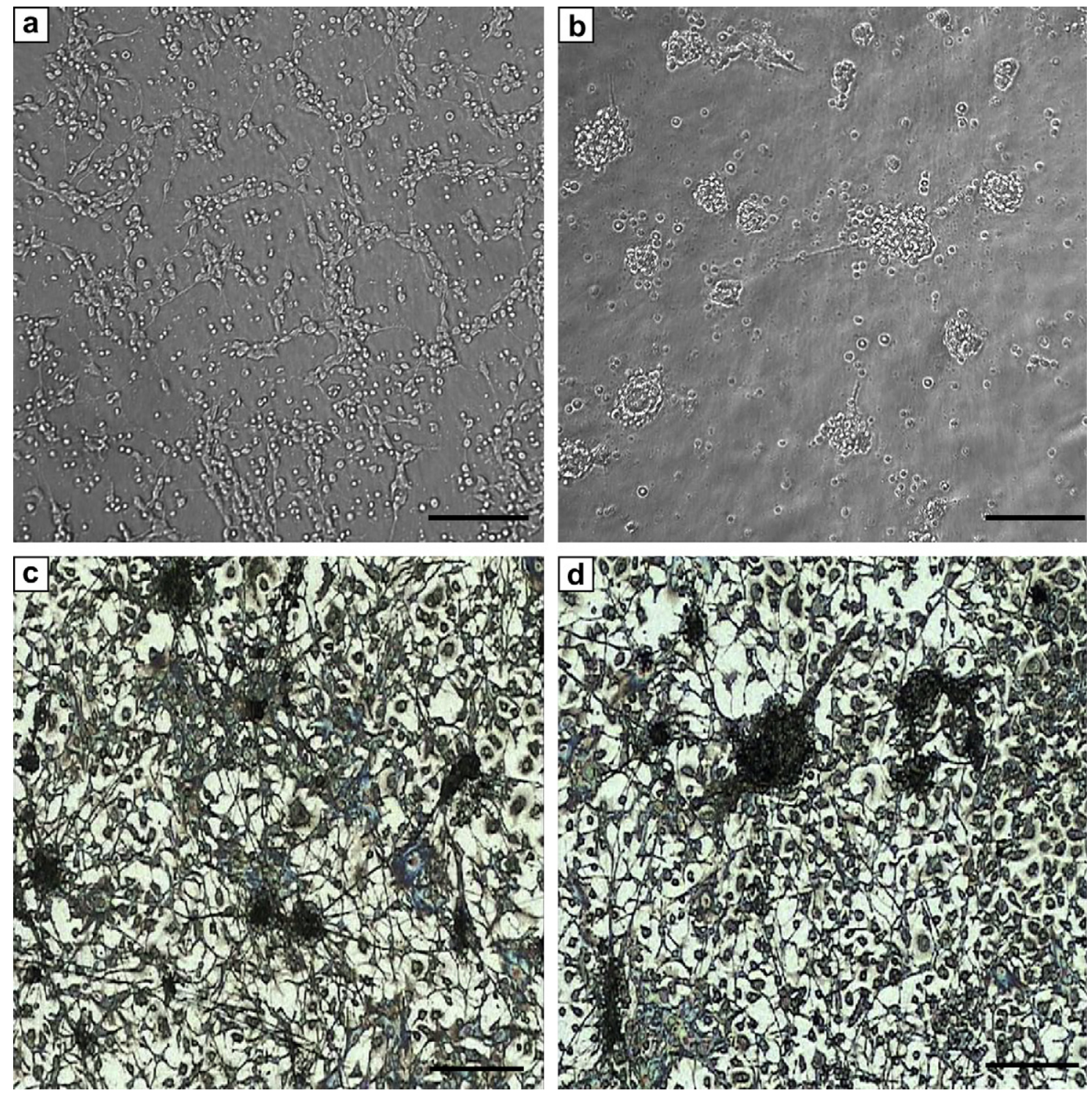

Fig. 2. Photomicrographs of cerebellar granule neurons cultured on (a) PDL, (b) TCPS, (c) n-type GaN, and (d) p-type GaN after $20 \mathrm{~h}$ of incubation. (scale bar $=100 \mu \mathrm{m})$. 


\subsection{LDH assay}

The toxic effect of substrates on the cultured cells was quantitatively determined by measuring the release of LDH into the culture medium. LDH activity of collected medium was measured by using LDH kit (Roche, USA) according to the protocol. The optical density of the LDH activity was read on an ELISA plate reader at $490 \mathrm{~nm}$ and reference wavelength at $630 \mathrm{~nm}$.

\section{Results}

\subsection{The effect on phosphorylation of Akt}

To address the possible mechanism of action of GaN on cultured neurons, we investigated whether Akt pathway participated in the regulation of behaviors of neurons cultured on
GaN surface because Akt has been shown to promote cell survival and prevent apoptosis [15]. Akt kinase activity correlated with its phosphorylation, so the Akt activity of cells cultured on n-type and p-type GaN was determined by measuring Akt phosphorylation in Western blot analysis. For comparison, TCPS and PDL-coated TCPS (is simply termed PDL, hereinafter) were also used to culture cells. Anti-phosphorylated Akt antibody shows that n-type and p-type GaN caused a high level of Akt phosphorylation, whereas both TCPS and PDL induced Akt phosphorylation at an extremely low level after $20 \mathrm{~h}$ of incubation (Fig. 1). At this time, cells showed extensive single cell adhesion on PDL (Fig. 2a) but showed cell-cell aggregation on TCPS (Fig. 2b). For the case of n-type and p-type GaN, cells exhibited similar adhesion behavior (Fig. 2c,d). Cell aggregates
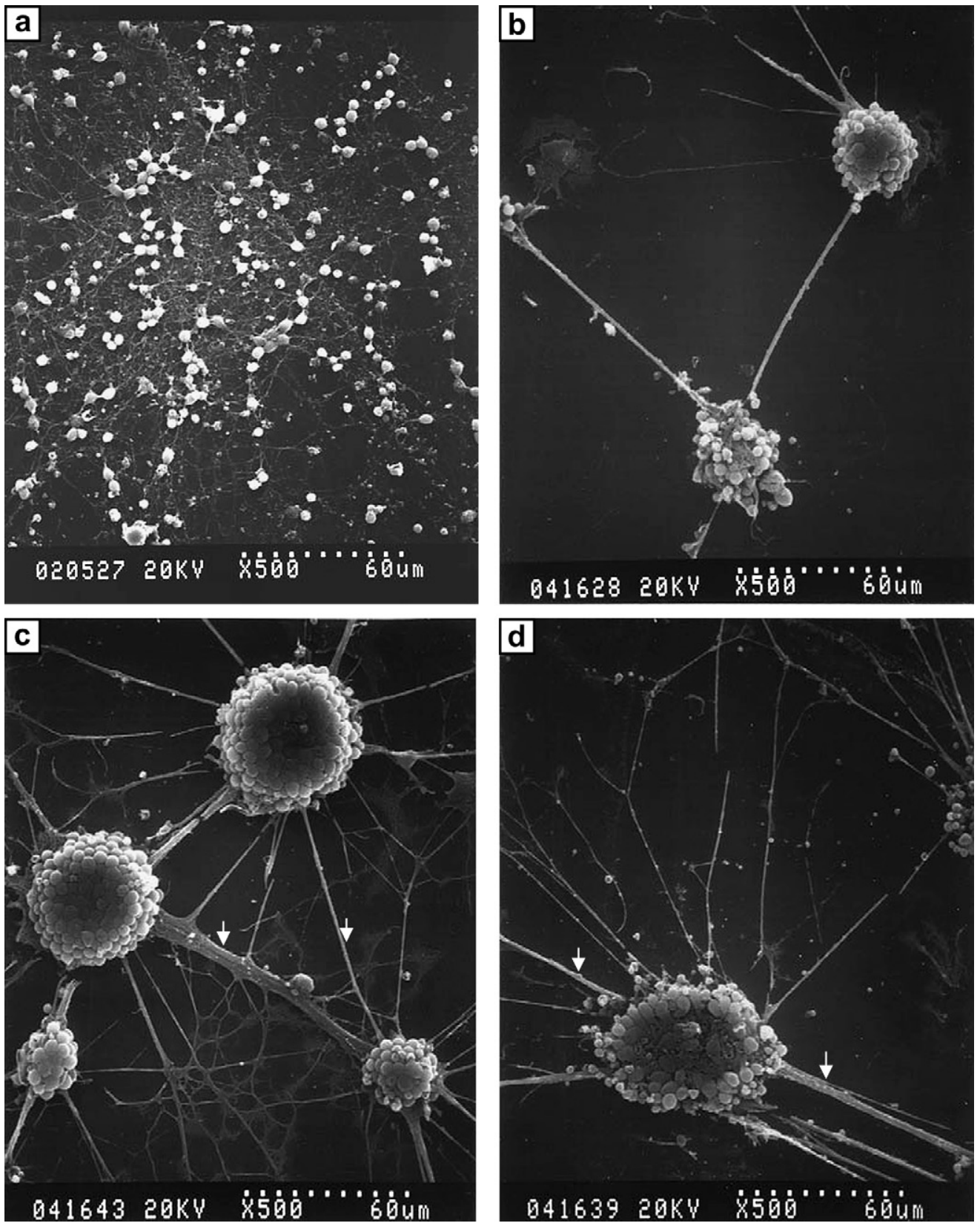

Fig. 3. SEM pictures of cerebellar granule neurons cultured on (a) PDL, (b) TCPS, (c) n-type GaN, and (d) p-type GaN after 8 days of incubation. Arrows in (c) and (d) indicate neurite growth in the straight path. 
and single cells were observed on both the types of GaN simultaneously. These results show that GaN exhibited different influences on the signal transduction and neuronal morphogenesis within a very short culture period.

\subsection{The effect on neurite fasciculation}

To analyze the effect of GaN on neurite fasciculation, the morphology of cerebellar granule neurons cultured on PDL, TCPS, n-type and p-type GaN was examined by SEM after incubation for 8 days. Fig. 3a shows neurons plated on PDL formed neurite networks with the defasciculated feature of the neurite. In contrast, n-type and p-type $\mathrm{GaN}$ induced the axonal fasciculation and exhibited a dense fiber network extending in all directions (Fig. 3c, d). These formed neurites on the surface of n-type and p-type $\mathrm{GaN}$ tended to grow in the straight path and formed minor bends of less than $17^{\circ}$ (arrows in Fig. 3), as measured through fractal analysis, which may be attributed to the stiff properties of microtubule polymer bundles [25]. Generally, dendritic outgrowth does not exhibit the
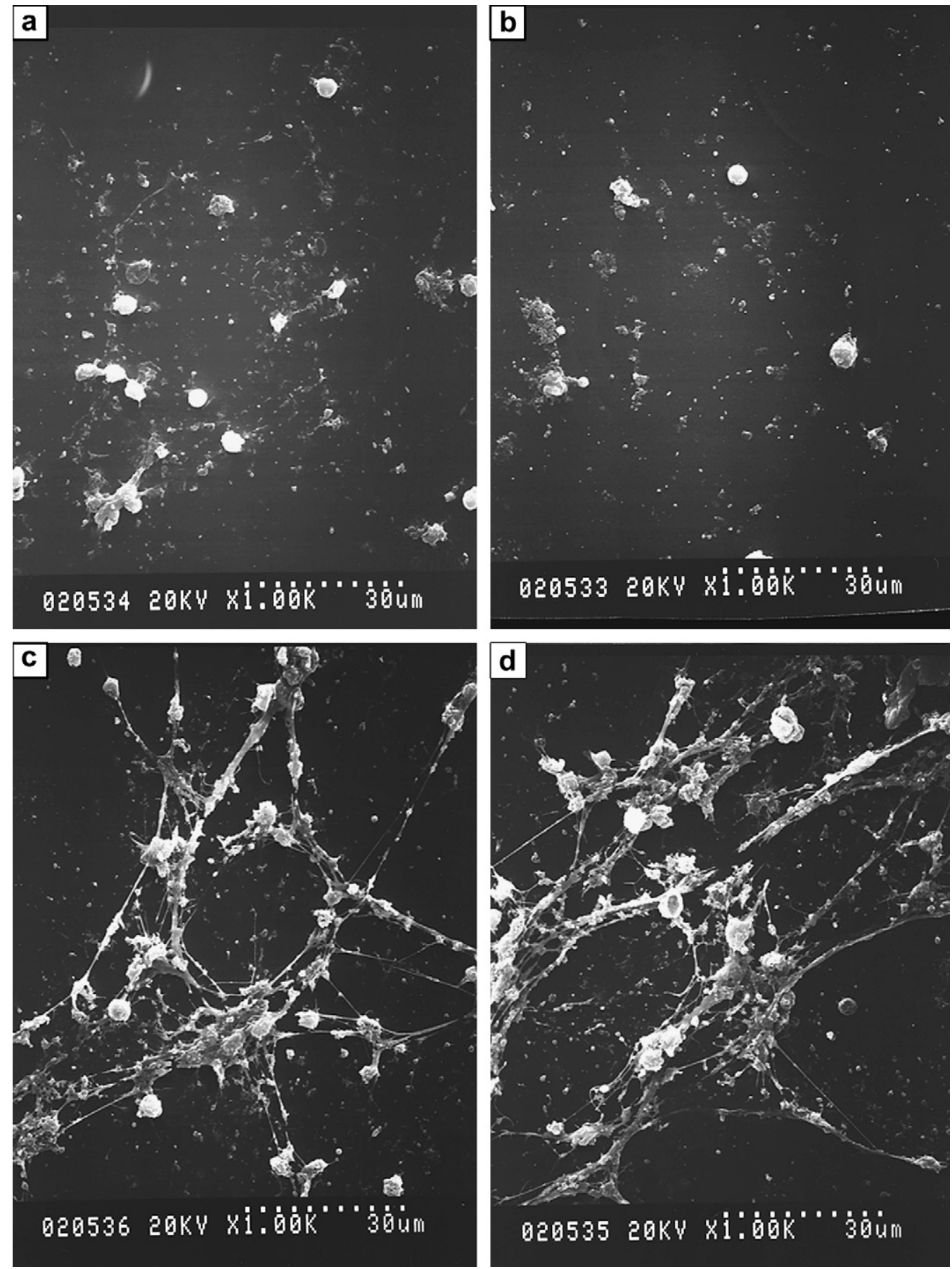

Fig. 4. SEM pictures of cerebellar granule neurons cultured on (a) PDL, (b) TCPS, (c) n-type GaN, and (d) p-type GaN after 8 days of incubation in the serum-free medium. 
long-distance characteristic of axonogenesis, and the dendritic branch angles vary across neuronal cell types $[1,26]$. Thus, it is reasonable to infer that axonal extension of granule neurons on the surface of n-type and p-type GaN. In addition, cells grew into compact neuronal aggregates on the surface of n-type and p-type GaN and intimate cell-cell contact was observed within the 3-D aggregate structure. A similar cell behavior was observed for neurons cultured on TCPS, but less neurites and neuronal aggregates were observed (Fig. 3b).

To further evaluate the effect of $\mathrm{GaN}$ itself on neurite development, cerebellar granule neurons were cultured on PDL, TCPS, n-type and p-type GaN in serum-free medium (Fig. 4). Clearly, neurons cultured on PDL and TCPS only showed individual adhesion after 8 days of incubation. Conversely, GaN not only maintained neuronal adhesion but also neurite outgrowth in the absence of serum, regardless of n-type or p-type. In general, the direct contact between cell and the substrate is the first step for cell adhesion onto the substrate, but it is known that cell-substrate adhesion is generally considered to be a complicated process involving adsorption of extracellular matrix proteins onto the substrate surface, especially for the presence of serum. Therefore, one can argue that GaN contributed to neurite outgrowth patterns via a more complex cell-substrate interaction that was enhanced by the presence of serum. Although such a possibility cannot be completely ruled out, Figs. 3 and 4 show that GaN promoted cell adhesion as well as induced neurite outgrowth simultaneously in the serum-dependent and -independent interactions.
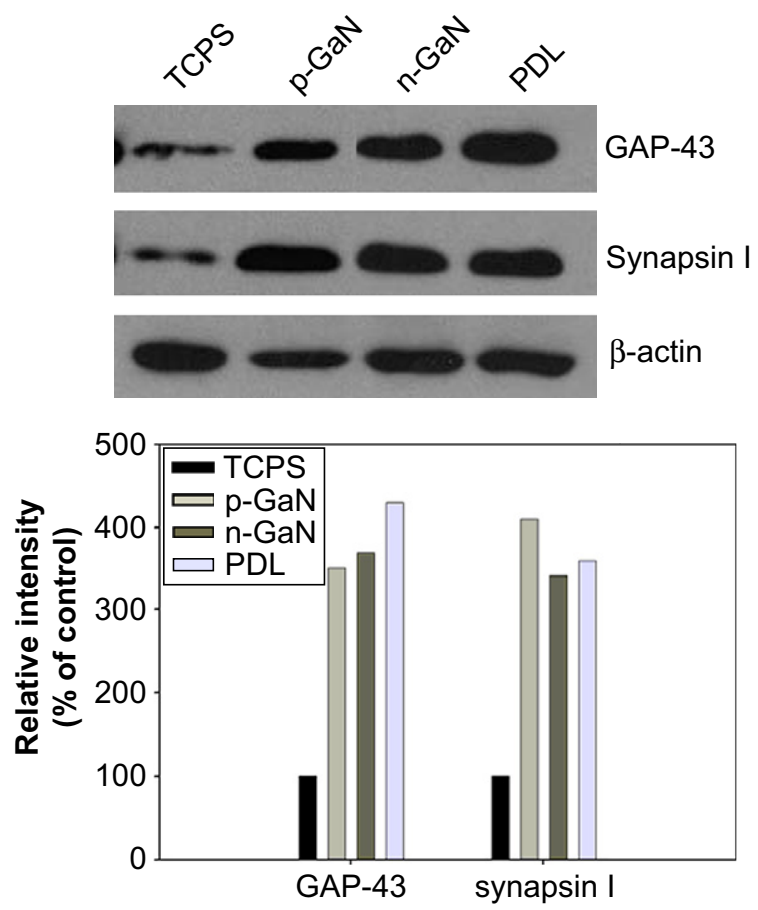

Fig. 5. Western blots were performed with anti-GAP-43, anti-synapsin I, and anti- $\beta$-actin antibodies for cerebellar granule neurons cultured on TCPS, n-type GaN, p-type GaN, and PDL after 8 days of incubation. The bottom panel indicates the relative intensities of GAP-43 and synapsin I levels, determined by band densitometry analysis. The ratio of the band intensities was expressed as a percentage of TCPS control.

\subsection{The effect on axonal growth and synaptogenesis}

To evaluate the effect of GaN on axonal growth and synaptogenesis, cerebellar granule neurons on PDL, TCPS, n-type and p-type $\mathrm{GaN}$ after 8 and 35 days of culture were prepared for Western blot analysis. A number of neurotypic proteins have been associated with neuron differentiation and neurite outgrowth. GAP-43 is preferentially distributed in the growth cone and elongating axon of developing neurons, whose expression can be correlated with axonal and neurite outgrowth in culture [27]. Figs. 5 and 6 show that GAP-43 levels were always low for cells cultured on TCPS, regardless of 8 or 35 days of culture. Compared to TCPS, there was considerable expression of GAP-43 for cells cultured on PDL and GaN after 8 days of incubation. This large increase in GAP-43 suggests that differentiation of neurons induced by PDL and GaN was similar and obvious. However, compared to $\mathrm{GaN}$, neurons cultured on PDL could not maintain the strong expression of GAP-43 after 35 days of culture. A similar result was observed for Western blot analysis of synapsin I (Figs. 5 and 6), a presynaptic protein involved in synapse formation and synaptic
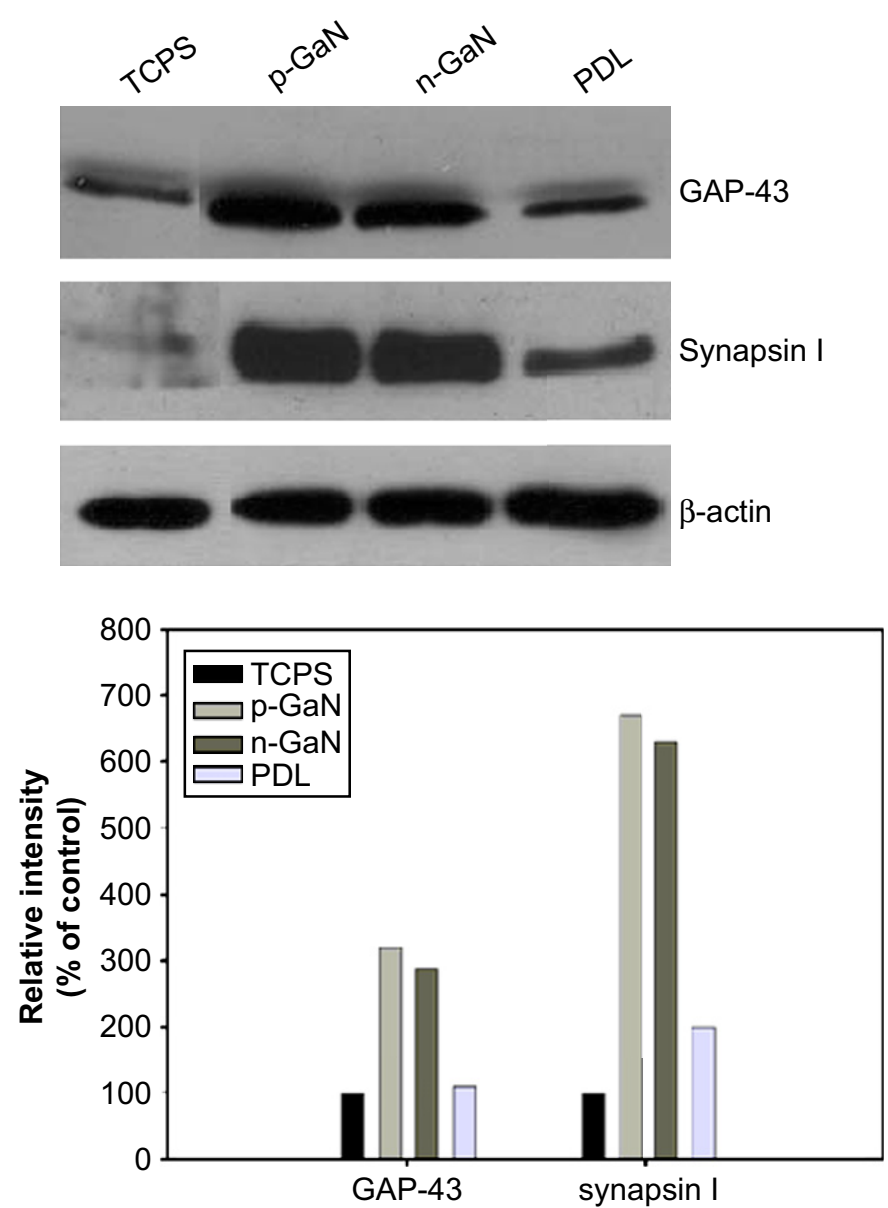

Fig. 6. Western blots were performed with anti-GAP-43, anti-synapsin I, and anti- $\beta$-actin antibodies for cerebellar granule neurons cultured on TCPS, n-type GaN, p-type GaN, and PDL after 35 days of incubation. The bottom panel indicates the relative intensities of GAP-43 and synapsin I levels, determined by band densitometry analysis. The ratio of the band intensities was expressed as a percentage of TCPS control. 
transmission as well as preferentially localized in axons, particularly concentrated in the distal axon and growth cone [28]. This indicates that GaN could maintain a neuron-favorable environment for axonal growth and synaptogenesis for a longer period than PDL, a standard substrate in the preparation of neuronal cultures.

For the next experiment, presynaptic vesicles were visualized by immunofluorescent labeling for the vesicle-associated proteins synapsin I and synaptophysin after 35 days of culture. Figs. 7a, b and 8a, b show that cells on PDL and TCPS were faintly stained for the expression of synapsin I and synaptophysin after a long-term culture period. In contrast, for cells cultured on n-type and p-type GaN, immunostaining for synapsin I (Fig. 7c, d) was concentrated in bright fluorescent puncta around cell bodies and along radially oriented axons. The distribution of synaptophysin for cells cultured on n-type and p-type GaN is shown in Fig. 8c, d. Basically, a similar pattern of localization was observed for the immunostaining expression of synapsin I and synaptophysin. Neighboring neuron aggregates were connected by axons and synaptic puncta distributed along the length of axons. This suggests that GaN maintained neurite network and neuronal function after a long-term culture period. In addition to synapsin I and synaptophysin, the immunostaining for MAP-2, the marker used to define the presence of dendrites [29], was also shown in Figs. 7 and 8. However, our immunocytochemical analysis failed to detect dendrites on both types of $\mathrm{GaN}$, which were MAP-2-negative. Therefore, the formation of functionally mature presynaptic release sites did not contact a postsynaptic apposition for cerebellar granule neurons cultured on $\mathrm{GaN}$ surface. The conclusion that cell-cell contact is not a prerequisite for the formation of a functional presynaptic release site is consistent with the previous finding of culturing rat hippocampal neurons [30].

\subsection{LDH assay}

Finally, the toxic effect of GaN on the long-term cultured neurons was quantitatively determined by measuring the release of $\mathrm{LDH}$ into the culture medium in the same experiments described for the Western blot analyses. $\mathrm{LDH}$ is a stable cytoplasmic enzyme and is abundantly present in central neurons [31]. Generally, LDH assay is a precise, fast and simple colorimetric method to quantify cytolysis when damage to the plasma membrane occurs [32]. As shown in Fig. 9, there was no difference in $\mathrm{LDH}$ release in the culture medium between neurons cultured on n-type and p-type GaN, but the significant difference was observed when both the types of GaN were compared to the PDL or TCPS $(p<0.05)$ after 35 days of culture. Therefore, similar to the morphological observation, GaN could improve the neuronal survival to reduce the neuronal death compared to the PDL and TCPS.
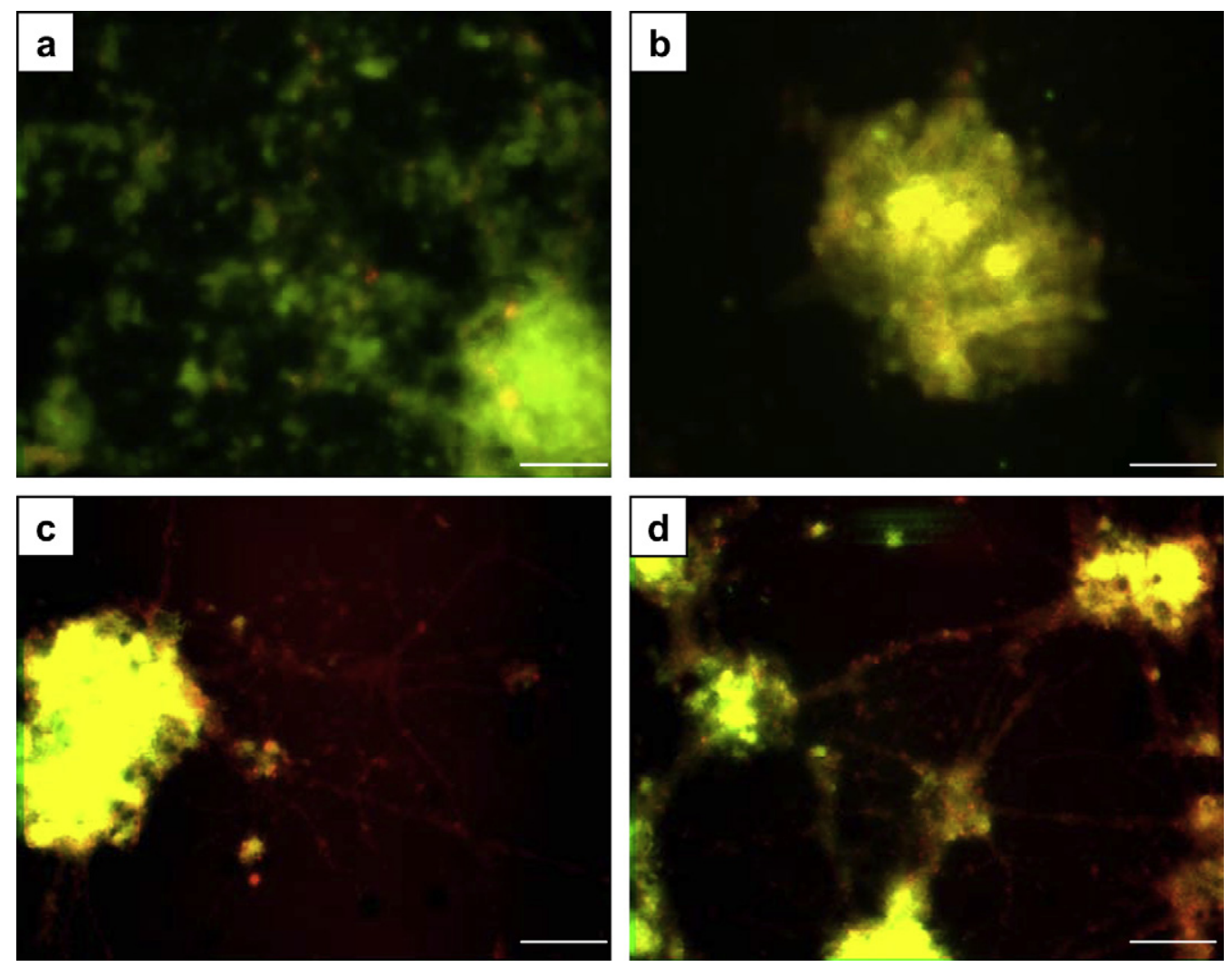

Fig. 7. Immunocytochemical staining of the presynaptic protein synapsin I and the dendrite marker MAP-2 in cerebellar granule neurons. Fluorescent photomicrographs represent cells on (a) PDL, (b) TCPS, (c) n-type GaN, and (d) p-type GaN after 35 days of culture. Synapsin I and MAP-2 labeling are red and green, respectively (scale bar $=100 \mu \mathrm{m})$. 

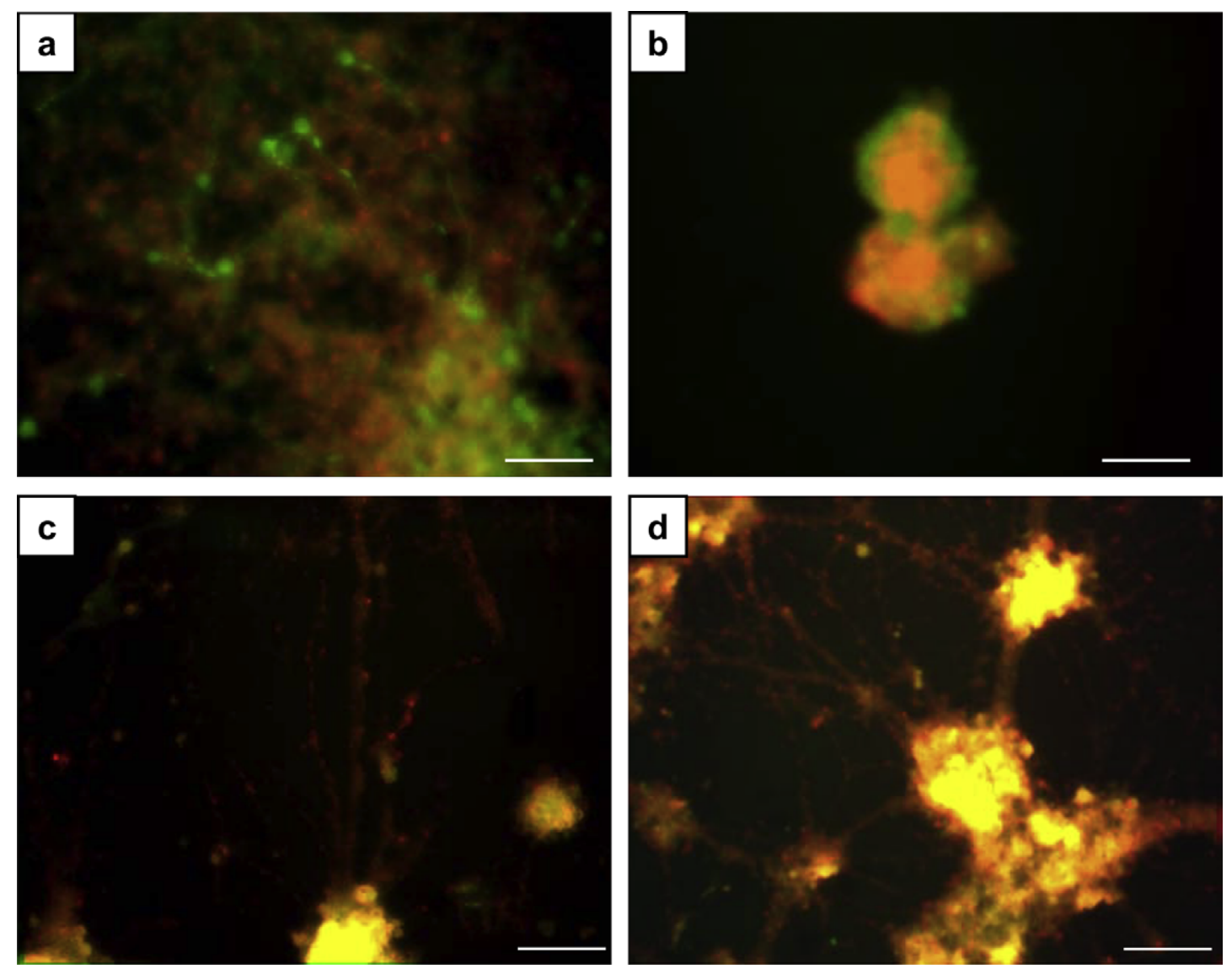

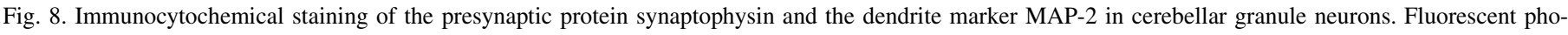

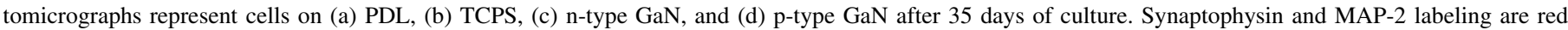
and green, respectively (scale bar $=100 \mu \mathrm{m}$ ).

\section{Discussion}

The purpose of this study is to investigate whether the neurite development and function still can be maintained on $\mathrm{GaN}$ after a long-term culture period. The substrates used in this study included TCPS, PDL, n-type and p-type GaN. It is known that biomaterial surface characteristics govern cellsubstrate interactions. Changes in cell-substrate interactions through the cell surface receptors corresponded to changes in cellular signaling events, as well as changes in cell survival and differentiation. Therefore, the ultimate cellular response may be resulted from the effect of signal transduction at an early stage of cell adhesion process. The anti-apoptosis role of the phosphatidylinositol 3-kinase (PI3-K) pathway has been well documented $[14,33]$. The importance of PI3-K pathway is to trigger a chain of phosphorylation reactions that include insulin and cell survival signals [34]. Akt is known to be a downstream target of PI3-K and plays an important role in signal transduction [13,14], which regulates cell survival, growth, glucose transport and energy metabolism [15]. In this study, we investigated whether Akt pathway participated in the regulation of survival of neurons cultured on $\mathrm{GaN}$ at an early stage and might involve additional events that occurred at later stages. Interestingly, Western blot analysis shows that PDL and TCPS exhibited a very low level of Akt phosphorylation, whereas both n-type and p-type GaN induced Akt phosphorylation to a high level during the first $20 \mathrm{~h}$ of incubation, as shown in Fig. 1. In addition, different cell distribution was observed on different substrates at this same culture period (Fig. 2). Both cell aggregates and single cells were observed on the GaN simultaneously, which was different from single cell adhesion on PDL and only cell aggregates on TCPS. Therefore, elucidation of the substrate-dependent, Akt-mediated differences in cell signaling and survival is important to bridge the gap between GaN semiconductor material and neuronal activities for developing a long-term used neurochip.

Fig. 3 shows GaN induced larger neuronal aggregates and axonal fasciculation to exhibit a dense fiber network after incubation of 8 days. Changes in the degree of neuron distribution and neurite fasciculation often reflect a balance between two competing forces: the interactions of cell-substrate and cell-cell [35]. Enhancement of cell-to-substrate adhesion produces monolayered cells and neurite branches (e.g., adhesive PDL substrate), while dominance of cell-cell interaction results in neuron aggregation and neurite-neurite fasciculation. Therefore, when cerebellar granule neurons were cultured on relatively low adhesive GaN surface, cell-cell interaction caused cell migration and aggregation as well as neurite fasciculation, resulting in the formation of a dense fiber 


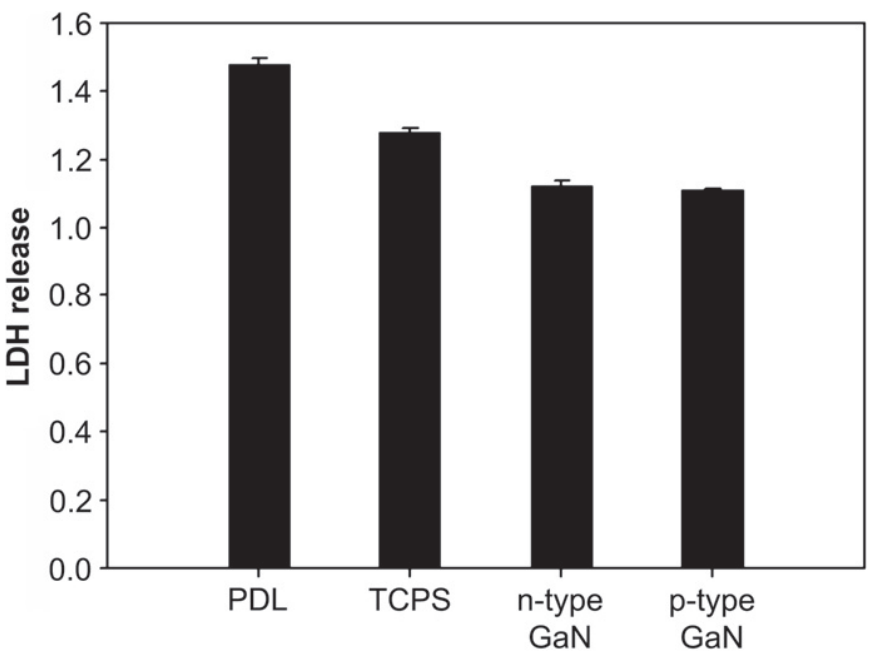

\begin{tabular}{|l|l|l|l|}
\hline & n-type GaN & p-type GaN & TCPS \\
\hline PDL & $*$ & $*$ & $*$ \\
\hline n-type GaN & & n.s. & * \\
\hline p-type GaN & & & $*$ \\
\hline
\end{tabular}

Fig. 9. LDH assay of cerebellar granule neurons cultured on TCPS, PDL, n-type $\mathrm{GaN}$ and p-type $\mathrm{GaN}$ after 35 days of incubation. Results represent mean \pm standard error of mean from three independent cultures and determinations. Asterisks indicate significant difference $(p<0.05)$ as determined by one-way ANOVA and post-hoc Duncan test.

network from gradually enlarging neuronal aggregates. In vivo, cerebellar granule neurons are tightly packed in the internal granule layer [36]; thus, neurons on GaN surface adopted physiological aggregated-structure resembling in vivo condition, which were different from the traditional monolayered morphology in vitro. Clearly, it is important to elucidate the interaction of neurons with the underlying substrate surface to regulate neuron adhesion and neurite development. Regardless of n-type or p-type GaN, such a phenomenon still could be observed even in the absence of serum, as shown in Fig. 4. Although the detailed mechanism by which $\mathrm{GaN}$ promotes expression of Akt is not clear, the function of Akt pathway also has the protective effect on serum-starved neurons after 8 days of incubation.

Although neurons cultured on GaN and PDL had different neuronal patterns after 8 days of incubation, expression of GAP-43 and synapsin I by Western blot analysis was similar at this time (Fig. 5). Therefore, it is difficult to discriminate the effects of GaN and PDL on axonal growth and synaptogenesis only for a short-term culture period. Different outcome occurred at later stages. Compared to GaN, neurons cultured on PDL could not exhibit the strong expression of GAP-43 and synapsin I after 35 days of culture. However, GaN still maintained a neuron-favorable environment for axonal growth and synaptogenesis over a longer period of time (Fig. 6). Parallel immunocytochemical observations confirmed the presence of the vesicle-associated proteins synapsin I and synaptophysin on both types of $\mathrm{GaN}$ after 35 days of culture (Figs. 7 and 8). It is known that neuronal polarity is controlled by the expression of axon markers such as synapsin I and synaptophysin [37-39] and it is important to develop electrophysiological properties of neuritic network with the acquisition of neuronal polarity for extracellular recording of cultured neurons [40]. This suggests that $\mathrm{GaN}$ maintained neuritic network and neuronal function after a long-term culture period. Finally, GaN could improve the neuronal survival to reduce the neuronal death compared to the PDL and TCPS (Fig. 9), which may result from the high expression of Akt phosphorylation at the initial culture period. These results further confirm that the GaN semiconductor material has the potential for developing a long-term used neurochip.

\section{Conclusion}

Survival and differentiation of cultured neurons are known to depend on the culture substrate. We report here the results of neuronal signal transduction at the early stage and neuronal development after a long-term culture period. In summary, the GaN substrate could activate Akt phosphorylation to a high level during the first $20 \mathrm{~h}$ of culture and could maintain neurite development and function after 35 days of culture. Therefore, culturing of cerebellar granule neurons on the GaN semiconductor material represents a feasible method to develop a GaN-based neurochip in the near future.

\section{Acknowledgement}

The authors thank National Science Council of the Republic of China for their financial support towards this research.

\section{References}

[1] Schalwig J, Muller G, Eickhoff M, Ambacher O, Stutzmann M. Gas sensitive GaN/AlGaN-heterostructures. Sens Actuators B Chem 2002; $87: 425-30$.

[2] Ambacher O, Smart J, Shealy JR, Weimann NG, Chu K, Murphy M, et al. Two-dimensional electron gases induced by spontaneous and piezoelectric polarization charges in $\mathrm{N}$ - and $\mathrm{Ga}$-face $\mathrm{AlGaN} / \mathrm{GaN}$ heterostructures. J Appl Phys 1999;85:3222-33.

[3] Dimitrow R, Murphy M, Smart J, Schaff W, Shealy JR, Eastman LF. Two-dimensional electron gases in Ga-face and N-face AlGaN/GaN heterostructures grown by plasma-induced molecular beam epitaxy and metalorganic chemical vapor deposition on sapphire. J Appl Phys 2000;87:3375-80.

[4] Yan J, Kappers MJ, Barber ZH, Humphreys CJ. Effects of oxygen plasma treatments on the formation of ohmic contacts to GaN. Appl Surf Sci 2004;234:328-32.

[5] Nakamura S, Fasol G. The blue laser diode. Heidelberg: Springer; 1997.

[6] Stringfellow G, Craford M. High brightness light emitting diodes: semiconductors and semimetals. San Diego, CA, USA: Academic Press; 1997.

[7] Maher M, Pine J, Wright J, Tai Y. The neurochips: a new multielectrode device for stimulating and recording from cultured neurons. J Neurosci Methods 1999;87:45-56.

[8] Zeck G, Fromherz P. Noninvasive neuroelectronic interfacing with synaptically connected snail neurons immobilized on a semiconductor chip. Proc Natl Acad Sci U S A 2001;98:10457-62. 
[9] Martinoia S, Bove M, Tedesco M, Margesin B, Grattarola M. A simple microfluidic system for patterning populations of neurons on silicon micromachined substrates. J Neurosci Methods 1999;87:35-44.

[10] Lein PJ, Banker GA, Higgins D. Laminin selectively enhances axonal growth and accelerates the development of polarity by hippocampal neurons in culture. Brain Res Dev Brain Res 1992;69:191-7.

[11] Young TH, Chen CR. Assessment of GaN chips for culturing cerebellar granule neurons. Biomaterials 2006;27:3361-7.

[12] Mori T, Ohwaki T, Taga Y, Shibata N, Koike M, Manabe K. Changes in surface composition of $\mathrm{GaN}$ by impurity doping. Thin Solid Films 1996;287:184-7.

[13] Kandel ES, Hay N. The regulation and activities of the multifunctional serine/threonine kinase Akt/PKB. Exp Cell Res 1999;253:210-29.

[14] Lawlor MA, Alessi DR. PKB/Akt: a key mediator of cell proliferation, survival and insulin responses? J Cell Sci 2001;114:2903-10.

[15] Hajduch E, Litherland GJ, Hundal HS. Protein kinase B (PKB/Akt) a key regulator of glucose transport? FEBS Lett 2001;492:199-203.

[16] McGuire CB, Snipes GJ, Norden JJ. Light-microscopic immunolocalization of the growth- and plasticity-associated protein GAP-43 in the developing rat brain. Brain Res 1988;469:277-91.

[17] Benowitz LI, Routtenberg A. GAP-43: an intrinsic determinant of neuronal development and plasticity. Trends Neurosci 1997;20:84-91.

[18] Baines AJ, Bennett V. Synapsin I is a spectrin-binding protein immunologically related to erythrocyte protein 4.1. Nature 1985;315:410-3.

[19] Bahler M, Greengard P. Synapsin I bundles F-actin in a phosphorylationdependent manner. Nature 1987;326:704-7.

[20] Wiedenmann B, Franke WW. Identification and localization of synaptophysin, an integral membrane glycoprotein of Mr 38,000 characteristic of presynaptic vesicles. Cell 1985;41:1017-28.

[21] Levi G, Aloisi F, Ciotti MT, Gallo V. Autoradiographic localization and depolarization-induced release of acidic amino acids in differentiating cerebellar granule cell cultures. Brain Res 1984;290:77-86.

[22] Sudhof TC, Czernik AJ, Kao HT, Takei K, Johnston PA, Horiuchi A, et al. Synapsins: mosaics of shared and individual domains in a family of synaptic vesicle phosphoproteins. Science 1989;245:1474-80.

[23] Binder LI, Frankfurter A, Rebhun LI. Differential localization of MAP-2 and tau in mammalian neurons in situ. Ann N Y Acad Sci 1986;466: 145-66.

[24] Navone F, Jahn R, Di Gioia G, Stukenbrok H, Greengard P, De Camilli P. Protein p38: an integral membrane protein specific for small vesicles of neurons and neuroendocrine cells. J Cell Biol 1986;103:2511-27.

[25] Katz MJ, George EB, Gilbert LJ. Axonal elongation as a stochastic walk. Cell Motil 1984;4:351-70.

[26] Brady S, Colman DR, Brophy P. Subcellular organization of the nervous system: organelles and their functions. In: Zigmond MJ, Bloom FE,
Landis SC, Roberts JL, Squire LR, editors. Fundamental neuroscience. San Diego: Academic Press; 1999. p. 71-106.

[27] Goslin K, Schreyer DJ, Skene JH, Banker G. Changes in the distribution of GAP-43 during the development of neuronal polarity. J Neurosci 1990;10:588-602.

[28] Chin LS, Li L, Ferreira A, Kosik KS, Greengard P. Impairment of axonal development and of synaptogenesis in hippocampal neurons of synapsin I-deficient mice. Proc Natl Acad Sci U S A 1995;92:9230-4.

[29] Navone F, Greengard P, De Camilli P. Synapsin I in nerve terminals: selective association with small synaptic vesicles. Science 1984;226:1209-11.

[30] Krueger SR, Kolar A, Fitzsimonds RM. The presynaptic release apparatus is functional in the absence of dendritic contact and highly mobile within isolated axons. Neuron 2003;40:945-57.

[31] Tholey G, Roth-Schechter BF, Mandel P. Activity and isoenzyme pattern of lactate dehydrogenase in neurons and astroblasts cultured from brains of chick embryos. J Neurochem 1981;36:77-81.

[32] Koh JY, Choi DW. Quantitative determination of glutamate mediated cortical neuronal injury in cell culture by lactate dehydrogenase efflux assay. J Neurosci Methods 1987;20:83-90.

[33] Leverrier Y, Thomas J, Mathieu AL, Low W, Blanquier B, Marvel J. Role of PI3-kinase in Bcl-X induction and apoptosis inhibition mediated by IL-3 or IGF-1 in Baf-3 cells. Cell Death Differ 1999;6:290-6.

[34] Vemuri GS, McMorris FA. Oligodendrocytes and their precursors require phosphatidylinositol 3-kinase signaling for survival. Development 1996;122:2529-37.

[35] Rutishauser U, Gall WE, Edelman GM. Adhesion among neural cells of the chick embryo. IV. Role of the cell surface molecule CAM in the formation of neurite bundles in cultures of spinal ganglia. J Cell Biol 1978;79:382-93.

[36] Ohga Y, Zirrgiebel U, Hamner S, Michaelidis TM, Cooper J, Thoenen H. Cell density increases Bcl-2 and Bcl-x expression in addition to survival of cultured cerebellar granule neurons. Neuroscience 1996;73:913-7.

[37] Ueda T, Greengard P. Adenosine $3^{\prime}: 5^{\prime}$-monophosphate-regulated phosphoprotein system of neuronal membranes. I. Solubilization, purification, and some properties of an endogenous phosphoprotein. J Biol Chem 1977;252(14):5155-63.

[38] Mandell JW, Banker G. Microtubule-associated proteins, phosphorylation gradients, and the establishment of neuronal polarity. Perspect Dev Neurobiol 1996;4:125-35.

[39] Jahn R, Schiebler W, Ouimet C, Greengard P. A 38,000-dalton membrane protein $(\sim 38)$ present in synaptic vesicles. Proc Natl Acad Sci U S A 1985;82:4137-41.

[40] Berger C, Reinhardt S, Rentrop M, Bachmann M, Weiser T, Link E, et al De novo acquisition of neuronal polarity in retinoic acid-induced embryonal carcinoma cells. Eur J Cell Biol 1997;74(3):230-45. 